\title{
Comparison of bacterial communities in soil samples with and without tomato bacterial wilt caused by Ralstonia solanacearum species complex
}

Ying Zhang ${ }^{1}$, Anna $\mathrm{Hu}^{1}$, Jianuan Zhou ${ }^{2}$, Wenfei Zhang ${ }^{1}$ and Peng $\mathrm{Li}^{1,2^{*}}$

\begin{abstract}
Background: Ralstonia solanacearum is one of the most notorious soil-borne phytopathogens. It causes a severe wilt disease with deadly effects on many economically important crops. The microbita of disease-suppressive soils are thought that they can contribute to the disease resistance of crop plants, thus, evaluation of the microbial community and their interaction characteristics between suppressive soil (SS) and conducive soil (CS) will help to understand resistance mechanism. To do this, the bacterial community structure, correlation analysis with soil chemical properties, interaction network of SS (nearly no disease in three years), and CS (suffered heavy bacterial wilt disease) were analyzed.
\end{abstract}

Results: A higher bacterial community diversity index was found in SS, the relative abundance of Nocardioides, Gaiella and norank_f_Anaerolineaceae were significantly more than that of the CS. Moreover, the relative abundance of main genera Bacillus, norank_o_Gaiellales, Roseiflexus, and norank_o_Gemmatimonadaceae were significantly more than that of the CS. Redundancy analysis at the genus level indicated that the available phosphate played a key role in the bacterial community distribution, and its role was negatively correlated with soil pH, organic matter content, alkali-hydrolyzable nitrogen, and available potassium contents. Interaction network analysis further demonstrated that greater diversity at the genus level existed in the SS network and formed a stable network. Additionally, the species of Mycobacterium, Cyanobacteria, and Rhodobiaceae are the key components that sustain the network stability. Seven clusters of orthologous groups exhibited significant differences between SS and CS. Moreover, 55 bacterial strains with distinct antagonistic activities to $R$. solancearum were isolated and identified from the healthy tomato plant rhizosphere soil of the CS.

Conclusions: Our findings indicate that the bacterial diversity and interaction network differed between the CS and SS samples, providing a good foundation in the study of bacterial wilt.

Keywords: Biological control, Conducive soils, Interaction network, Rhizosphere bacteria, Ralstonia solanacearum, Suppressive soils, Tomato

\footnotetext{
* Correspondence: dayuleepong@163.com

1 Ministry of Education Key Laboratory for Ecology of Tropical Islands, College

of Life Sciences, Hainan Normal University, Haikou 571158, China

${ }^{2}$ Guangdong Laboratory for Lingnan Modern Agriculture, Integrative

Microbiology Research Centre, Guangdong Province Key Laboratory of

Microbial Signals and Disease Control, College of Agriculture, South China

Agricultural University, Guangzhou 510642, China
}

C The Author(s). 2020 Open Access This article is licensed under a Creative Commons Attribution 4.0 International License, which permits use, sharing, adaptation, distribution and reproduction in any medium or format, as long as you give appropriate credit to the original author(s) and the source, provide a link to the Creative Commons licence, and indicate if changes were made. The images or other third party material in this article are included in the article's Creative Commons licence, unless indicated otherwise in a credit line to the material. If material is not included in the article's Creative Commons licence and your intended use is not permitted by statutory regulation or exceeds the permitted use, you will need to obtain permission directly from the copyright holder. To view a copy of this licence, visit http://creativecommons.org/licenses/by/4.0/. The Creative Commons Public Domain Dedication waiver (http://creativecommons.org/publicdomain/zero/1.0/) applies to the data made available in this article, unless otherwise stated in a credit line to the data. 


\section{Background}

Tomato (Solanum lycopersicum) is one of the most commonly cultivated vegetables in the world; however, the soil-borne disease caused by Ralstonia solanacearum species complex (RSSC) is a serious threat to tomato production. Moreover, more than 200 hosts in 54 botanical families can be infected by the members of RSSC [1], leading to severe economic and social impact worldwide $[2,3]$. RSSC can exist in the soil for many years, meaning that infected fields are less likely to successfully cultivate susceptible plants [4].

Disease-suppressive soils are exceptional ecosystems. It is widely thought that the soil microbiota contribute to the disease resistance of crop plants $[5,6]$. In recent years, increasing evidences have been reported for suppressing several soil-borne pathogens causing Fusarium wilt [7], potato common scab [8], damping-off disease [9], sugar beet wilt [10], and bacterial wilt [11]. In addition, further research showed that the diversity of the soil microbial community is particularly crucial for maintaining the disease suppressing capacity, which can affect the colonization success of additional species [12, 13]. Some beneficial bacteria have been introduced into soils to increase the microbial community diversity or enhance the resistance to RSSC [14, 15].

The tomato cultivar "Lingshui cherry tomato" which is well known for its unique flavor, is cultivated in large area and it is honored as China's national geographical indication products. However, due to long-term continuous monoculture, large areas of tomato fields suffered severe bacterial diseases in recent decades. Despite consistent tomato culturing and management patterns, the tomato grew well in some fields. In this study, we aimed to evaluate the differences in soil bacterial diversity and soil chemical properties between suppressive soil (SS, nearly no disease in 3 years) and the conducive soil (CS, suffered heavy bacterial wilt disease), with the goal of suppressing plant disease and protecting plant health.

Herein, a high-throughput sequencing technology was used to explore the differences in bacterial diversity between SS and CS. In addition, the soil chemical properties, bacterial community composition, network analysis and clusters of orthologous groups (COGs) were analyzed. Importantly, 55 bacterial strains with excellent antagonistic ability against $R$. solanacearum from the rhizosphere soil of healthy tomato plants were isolated and identified. This information provides more biocontrol resources for the control of bacterial wilt.

\section{Results}

Bacterial diversity assessment of the SS and CS samples In order to determine whether the microbial community functioned to sustain tomato health, we identified the difference in disease incidence of tomato plants cultivated under four growing conditions: SS, CS, CS with heat treatment, and sterile nutrient soil inoculated with the $R$. solanacearum suspension. The results demonstrated that all of the tomato plants showed wilt symptoms after 4 days of $R$. solanacearum suspension inoculation. The tomato plants cultivated in CS showed typical wilt symptoms and nearly $80 \%$ of plants wilted. Tomato plants grown in SS and the heat-treated soil exhibited no plant wilt (supplemental information, S1). The bacterial diversity of soil samples collected from SS and CS was assessed using phylotype taxonomy. The results revealed a total of 3041 operational taxonomic units (OTUs). The core OTU number was 2488 , and the $\overline{S S}$ and CS exhibited 330 and 220 unique OTUs, respectively (Fig. 1a). Furthermore, the result of Student's $t$-test indicated that the Sobs index of the OTU level of SS and CS samples was significant ( $p=0.002216$; Fig. $1 \mathrm{~b})$.

\section{Main bacterial composition of SS and CS}

The primary bacterial genera of the SS samples were $B a$ cillus (relative abundance 7.18\%), norank_o_Gaiellales (5.20\%), norank_c_Acidobacteria (3.28\%), Nocardioides (2.31\%), Nitrospira (2.74\%), norank_c_KD4-96 (1.82\%), norank $f \_X a n t h o b a c t e r a c e a e ~(1.99 \%)$. The genera Bacillus (3.95\%), norank_o_Gaiellales (3.94\%), norank_c_ Acidobacteria (3.76\%), Nocardioides (3.77\%), Gaiella (2.96\%) norank_c_KD4-96 (2.47\%), Roseiflexus (2.49\%), and norank $f \_$Anaerolineaceae $(2.41 \%)$ were the dominate groups of CS samples (Fig. 2). In addition, principal coordinates analysis (PCoA) revealed that the bacterial communities of SS and CS were distinct, and the PC1 axis showed $56.74 \%$ variation in the bacteria community between SS and CS (Fig. 3). The relative abundance of genera Nocardioides, Gaiella and norank_f_Anaerolineaceae between SS and CS reached significant ( $95 \%$ confidence interval, $\mathrm{CI} ; 0.01<p<0.05)$. In addition, the relative abundance of genera Bacillus, norank_o_Gaiellales, Roseiflexus, and norank_o_Gemmatimonadaceae were significant (95\% CI, $p<0.01$; Fig. 4).

\section{Chemical properties and redundancy analysis (RDA) of SS and CS}

No significant difference was observed for alkalihydrolyzable nitrogen (AHN) content of the SS and CS samples. The $\mathrm{pH}$, organic matter $(\mathrm{OM})$ content, and rapidly available potassium (RAK) of SS were significantly lower than the CS sample $(p<0.05$, Table 1$)$, but the content plant rapidly available phosphate (RAP) in SS was significantly higher than CS. RDA analysis at genus level revealed that RAP played a key role in the difference in bacterial community distribution between SS and CS, and it was negatively correlated with the other four chemical contents (Fig. 5). 


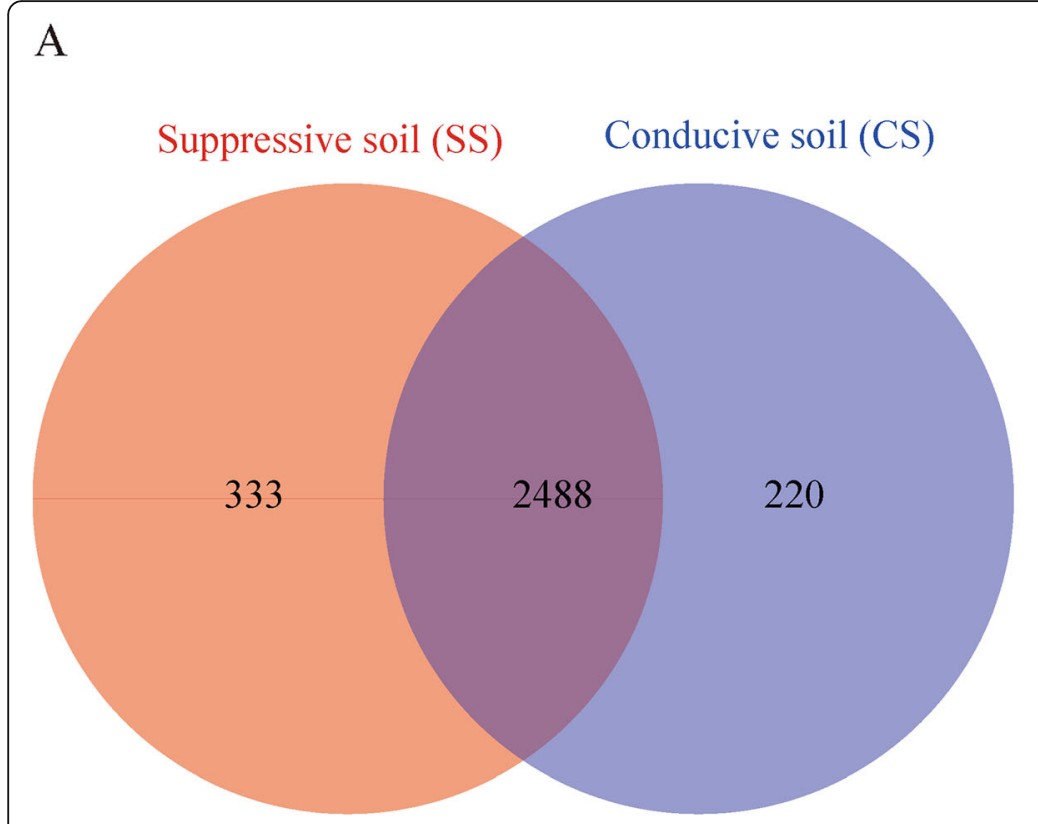

B

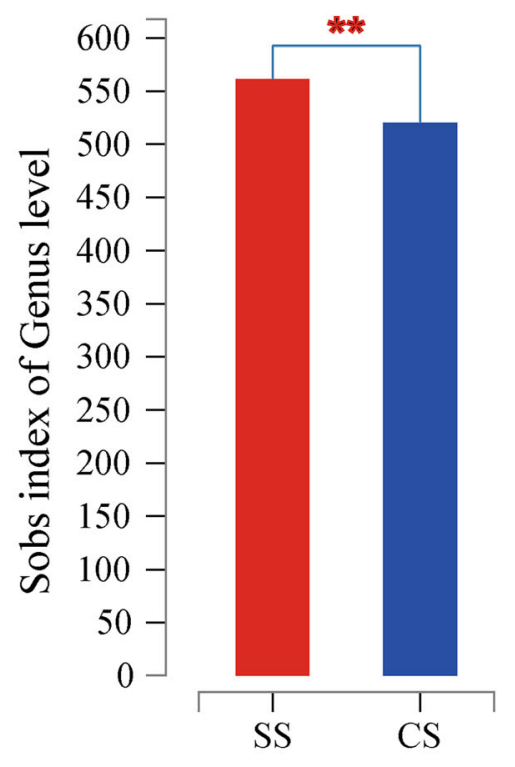

(Soil groups)

Fig. 1 Venn analysis of shared and unique OTUs between suppressive soil (SS) and conducive soil (CS) samples a. OTUs defined by $97 \%$ sequence similarity and Student's $t$-test of OTU level between suppressive soil (SS) and conducive soil (CS) $\mathbf{b}$. ${ }^{* *} p \leq 0.01$

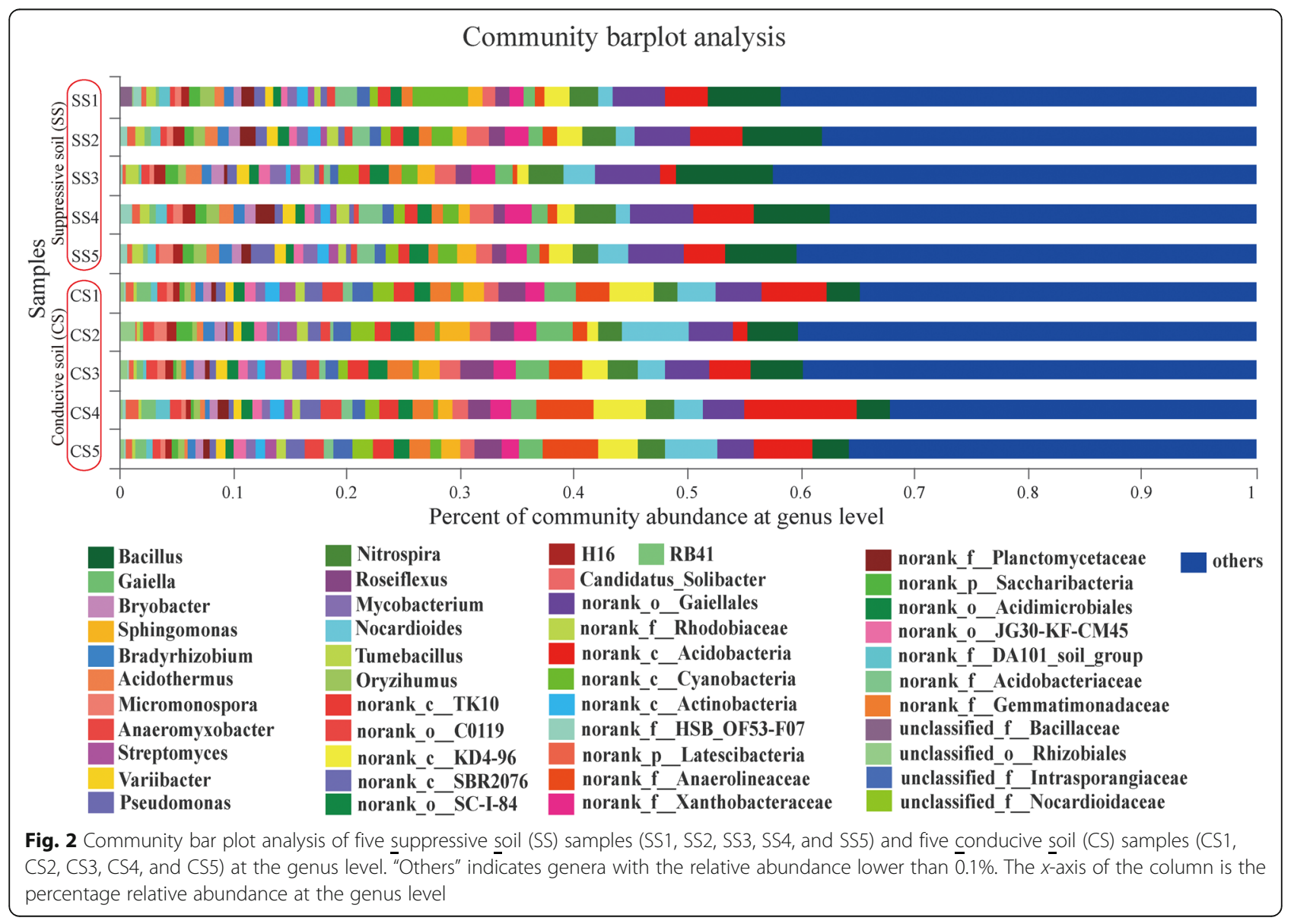




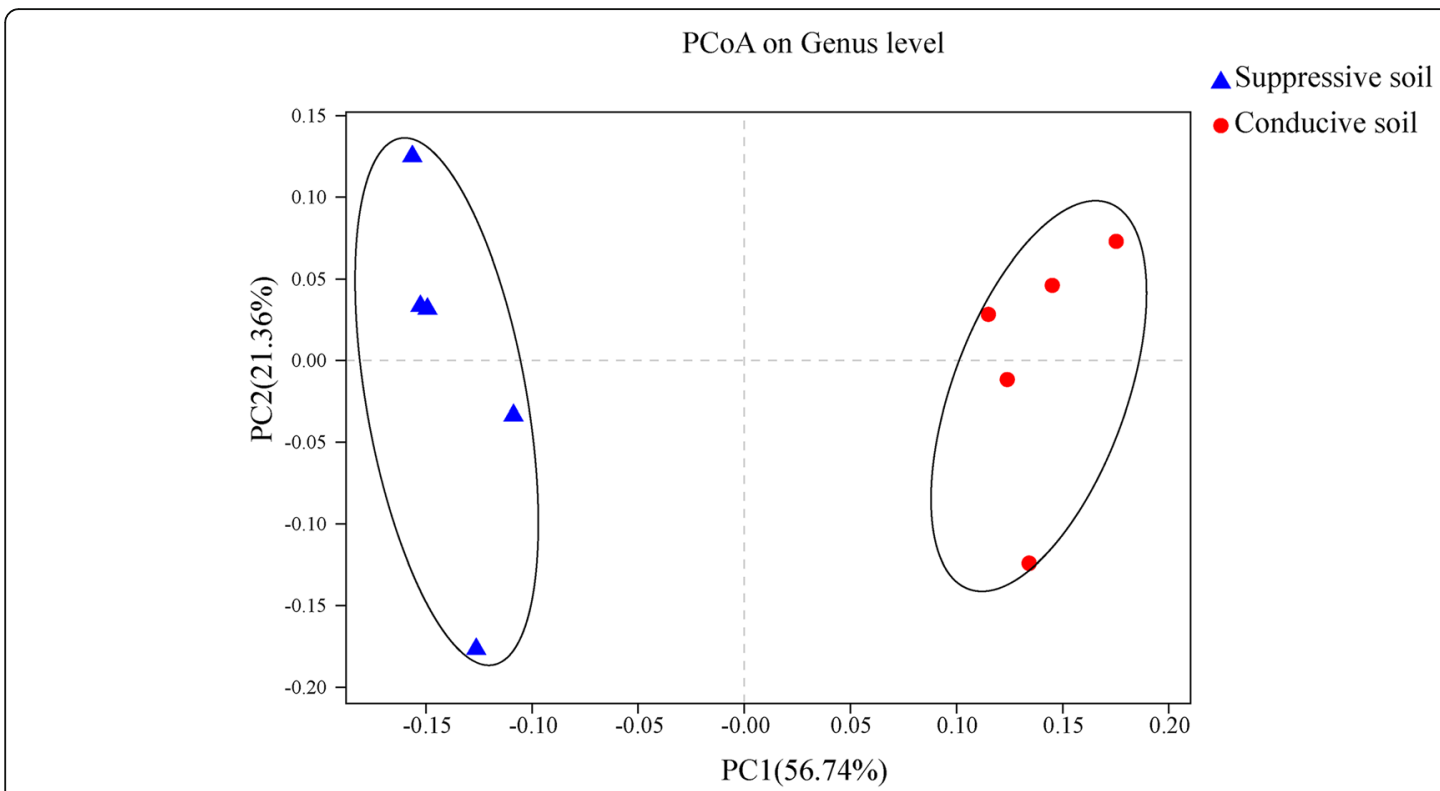

Fig. $3 \mathrm{PCOA}$ analysis at the genus level between suppressive soil (SS) and conducive soil (CS). The $\beta$-diversity was calculated based on the Bray-Curtis algorithm

\section{Network analysis of SS and CS}

Network analysis of the 30 most abundant genera revealed the interaction relationships of SS and CS, respectively. The results indicated that there were extensive interactions among the identified genera. In the SS (Fig. 6a), the 30 most abundant genera were from 10 phyla, including 10 genera from Actinobacteria, six genera from Proteobacteria, four genera from Acidobacteria, three genera from Chloroflexi, two genera from Firmicutes, and one genus each from Nitrospirae, Saccharibacteria, Planctomycetes, Cyanobacteria, and Gemmatimonadetes, respectively. Bacteria from Mycobacterium, Rhodobiaceae and Cyanobacteria showed interaction relationships with five, seven, and seven other genera, respectively. In the CS samples (Fig. 6b), these genera were only from

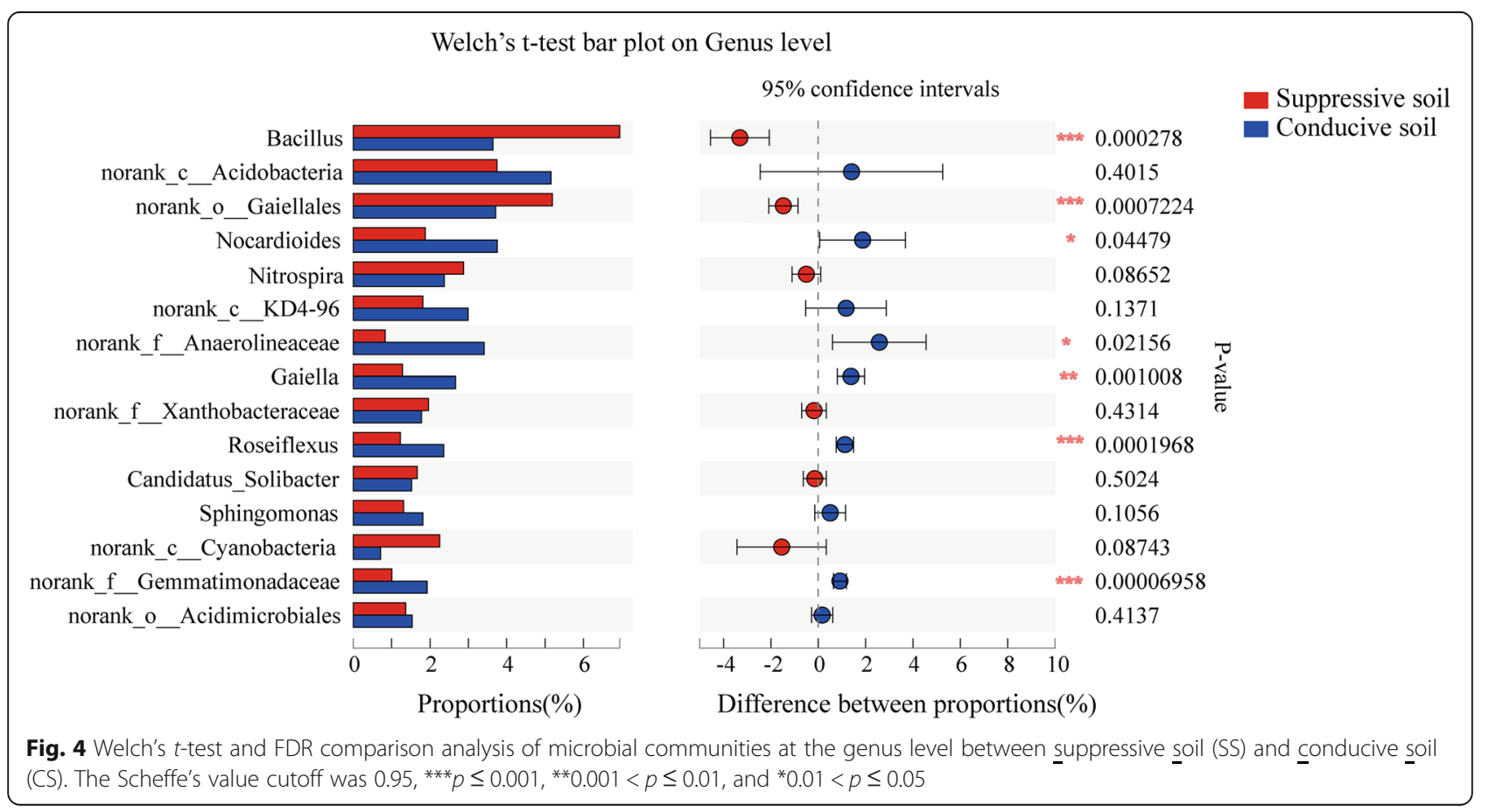


Table 1 The suppressive and conducive soil chemical properties

\begin{tabular}{|c|c|c|}
\hline Properties & Healthy soils $(\boldsymbol{n}=5)$ & Diseased soils $(\boldsymbol{n}=5)$ \\
\hline Location & N $18^{\circ} 29^{\prime} 51^{\prime \prime}$, E $109^{\circ} 56^{\prime} 54^{\prime \prime}$ & $\mathrm{N} 18^{\circ} 32^{\prime} 47^{\prime \prime}, \mathrm{E} 110^{\circ} 3^{\prime \prime} 1^{\prime \prime}$ \\
\hline $\mathrm{pH}$ & $5.19 \pm 0.16$ & $6.64 \pm 0.14 * *$ \\
\hline $\mathrm{OM}(\%)$ & $0.85 \pm 0.13$ & $1.15 \pm 0.082 *$ \\
\hline RAP (mg/kg) & $152.02 \pm 10.37$ & $86.95 \pm 5.58$ ** \\
\hline RAK (mg/kg) & $102.34 \pm 8.46$ & $247.69 \pm 54.68 * *$ \\
\hline $\mathrm{AHN}(\mathrm{mg} / \mathrm{kg})$ & $35.77 \pm 3.18$ & $39.21 \pm 2.82$ \\
\hline
\end{tabular}

seven phyla, such as the nine genera from Actinobacteria, six genera from Proteobacteria, six genera from Chloroflexi, four genera from Acidobacteria, one genus from Gemmatimonadetes, Nitrospirae, and Firmicutes, respectively.

\section{Analysis of the COGs with significant differences}

COG function prediction was performed and compared between SS and CS samples. The COGs with significant differences were further investigated. There were seven COGs that were significantly different, such as the group $\mathrm{S}$ (function unknown), $\mathrm{H}$ (coenzyme transport and metabolism), A (RNA processing and modification), F (nucleotide transport and metabolism), and D (cell cycle control, cell division, chromosome partitioning). The groups $\mathrm{C}$ (energy production and conversion) and $\mathrm{Z}$ (cytoskeleton) were very distinct (Fig. 7).

\section{Isolation and identification of antagonistic strains}

Few tomato plants in the CS field grew well. We collected the rhizosphere soil of three healthy tomato plants and isolated the cultural bacteria. Using the inhibition zone method, 55 bacterial strains with distinct antagonistic activities against $R$. solancearum strain EP1 were identified by sequencing their $16 \mathrm{~S} r D N A$ sequences (Table 2). The basic local alignment search tool (BLAST) results showed that these strains belong to the genera Bacillus (17 strains), Pseudomonas (10 strains), Sphingobacterium (10 strains), Chryseobacterium (9 strains), Serratia (four strains), Cellulosimicrobium (one strain), Staphylococcus (one strain), Fictibacillus (one strain), Microbacterium (one strain), and Paenibacillus (one strain).

\section{Discussion}

Previous studies have compared the microbial species abundance and diversity of bacterial wilt disease outbreak in soil samples [16-18]. Here, the microbial relative abundances and diversities of SS and CS were

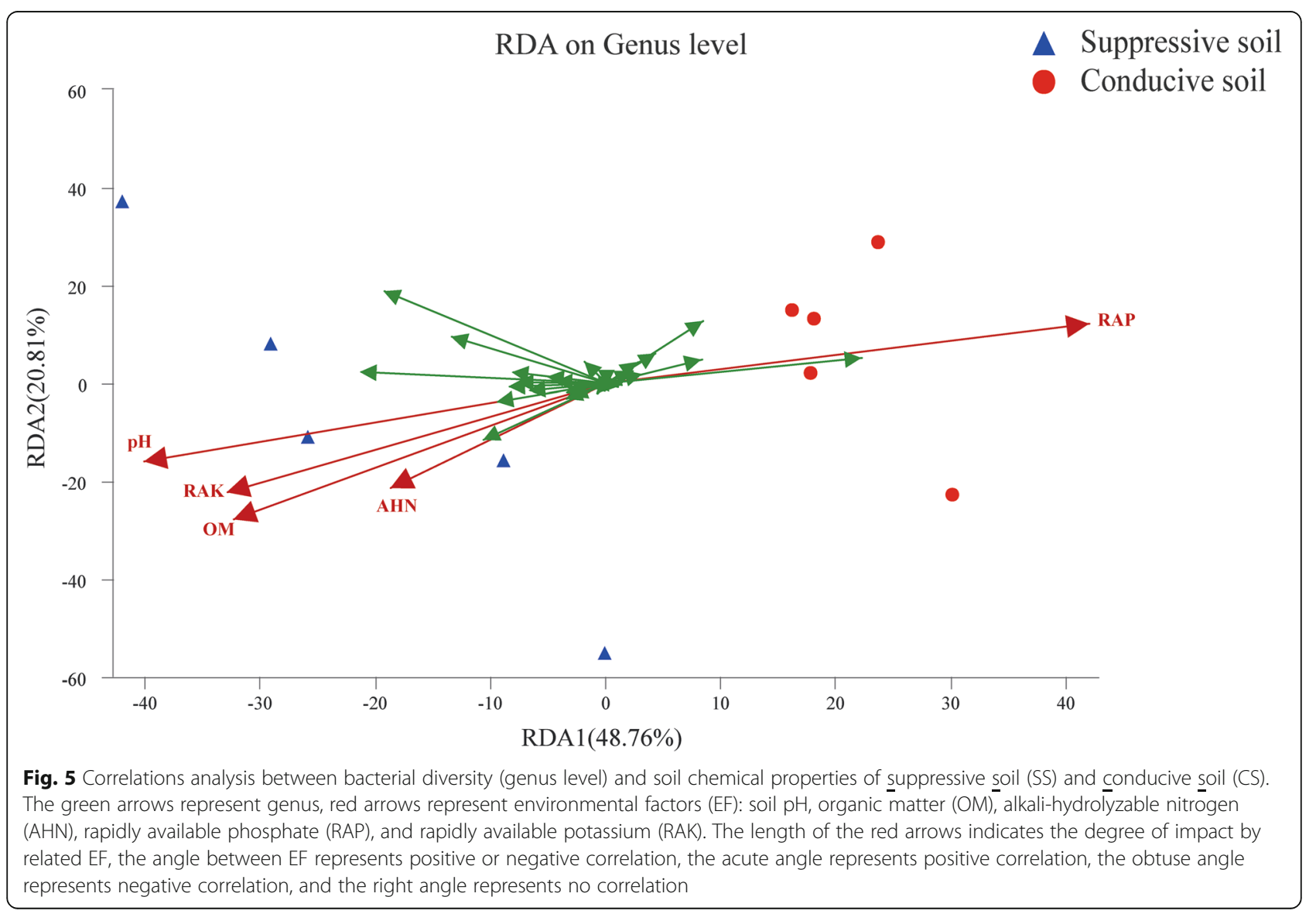




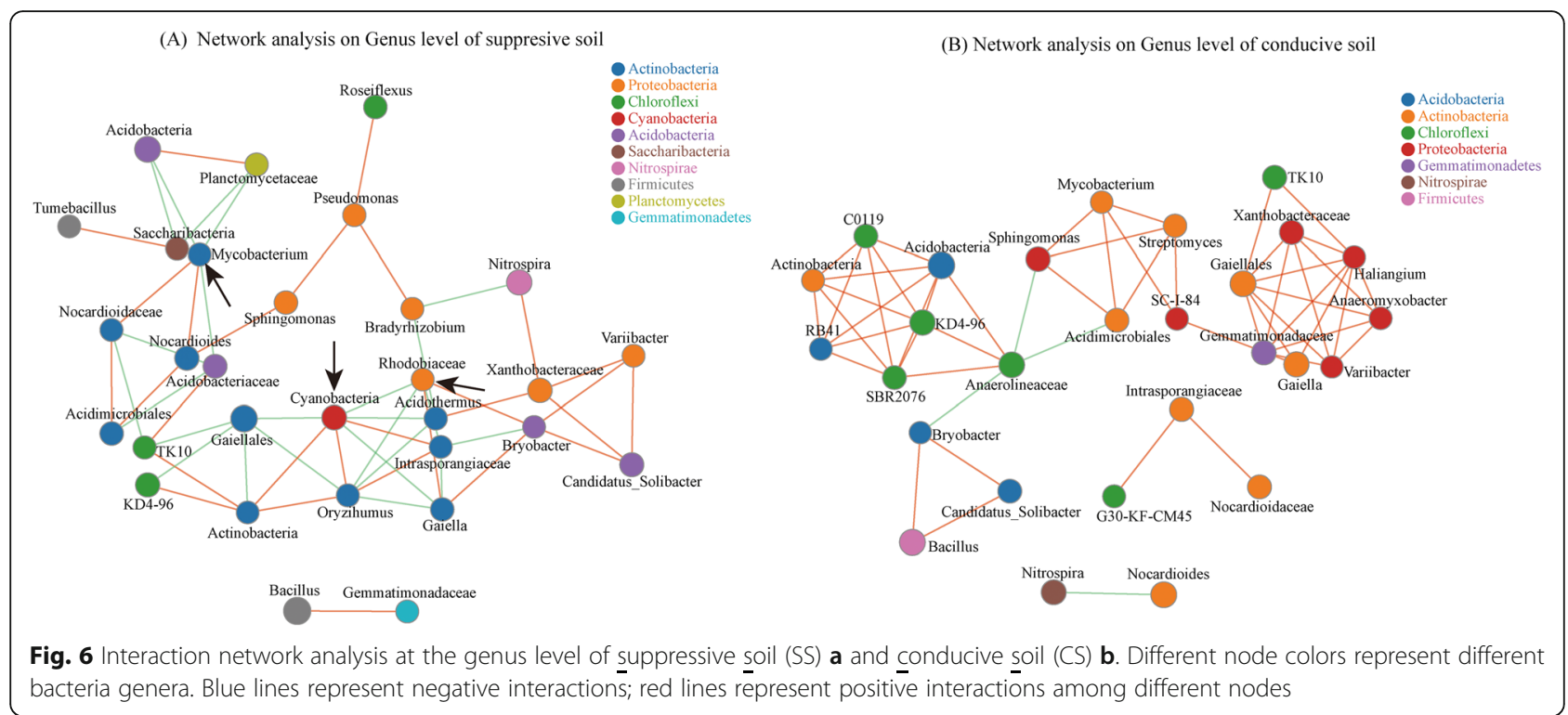

determined in addition to the associated soil chemical properties, microbial networks and COG groups with significant differences. Notably, we also isolated and identified 55 bacteria strains with excellent antagonistic activities to $R$. solanacearum strain EP1.

Results of Sobs index of the OTU level, main bacterial community distribution and PCoA indicated that significant differences in bacterial community composition exist between SS and CS (Figs. 1-3). Based on the result of Welch's t-test $(95 \% \mathrm{CI})$ at the genus level, the relative abundances of Bacillus, norank_c_Gaiellales, Roseiflexus, and norank_f_Gemmatimonadaceae were statistically significant (Fig. 4). Thus, the relative abundances of these four genera changed distinctly as bacterial wilt progressed. Numerous studies have proved that the $\mathrm{Ba}$ cillus species are beneficial microorganisms, producing a vast array of biologically active molecules that inhibit pathogens [19]. The cyclic lipopeptides antimicrobial compounds produced by Bacillus species, such as surfactin, iturin, and fengycin, have been well studied and applied for their antagonistic activities in reducing diseases caused by $R$. solanacearum [20], Rhizoctonia solani [21], Pythium aphanidermatum [22], and Podosphaera fusca [23]. In this study, the relative abundances of Bacillus in SS samples were higher than that in CS samples. Moreover, the result of antagonistic strain isolation and identification from the healthy tomato plant roots was also supported these data, for 17 Bacillus strains were found among the 55 antagonistic strains. These results further demonstrate that the Bacillus species is one key bacterial group for protecting plant health. In addition, the strains of Sphingobacterium, Chryseobacterium, Serratia, Cellulosimicrobium, Staphylococcus, Fictibacillus, Microbacterium, and Paenibacillus were also found with antagonistic activity against $R$. solanacearum in our study, however, based on our best understanding, which

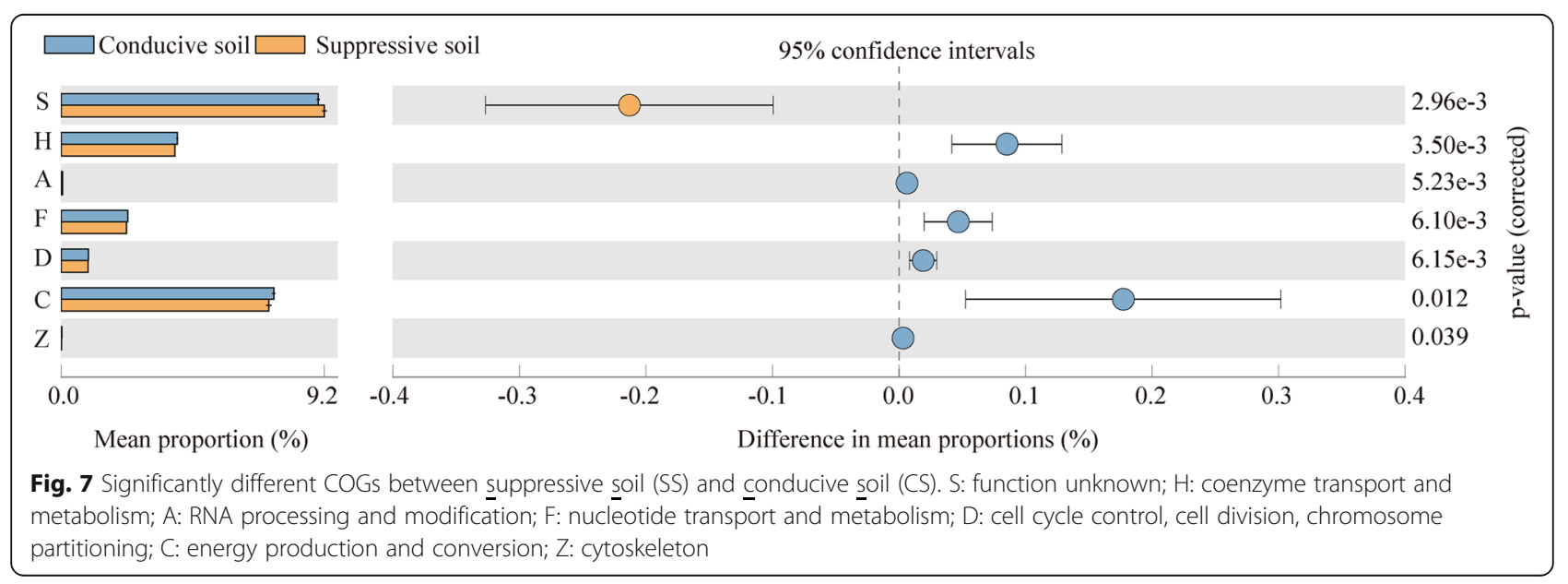


Table 2 The antagonistic strains against $R$. solanacearum strain EP1

\begin{tabular}{lll}
\hline Genus & Strain number & GenBank accession No. \\
\hline Bacillus & 17 & MN410647-48, 51-59, 61-62,71,74, 98, 70 \\
Pseudomonas & 10 & MN410664-65, 68-69, 75-76, 79, 89, 92, 94 \\
Sphingobacterium & 10 & MN410666-67, 72-73, 81-82, 85-86, 93, 96 \\
Chryseobacterium & 9 & MN410677, 80, 83-84 87-88, 90-91, 95 \\
Serratia & 4 & MN410670, 78,91,99 \\
Staphylococcus & 1 & MN410649 \\
Fictibacillus & 1 & MN410650 \\
Microbacterium & 1 & MN410660 \\
Cellulosimicrobium & 1 & MN410663 \\
Paenibacillus & 1 & MN410701 \\
\hline
\end{tabular}

were not so extensive reported. Thus, our study provides new resources for future biological control of bacterial wilt.

Soil is considered a highly complex and dynamic ecosystem [24], and the results of a recent study demonstrate that the formation of disease suppressive soils after a disease outbreak is likely due to the subsequent assembly of beneficial microbiota in the plant rhizosphere [25]. Network analysis can provide information regarding the symbiotic relationships of species in environmental samples, as well as species interactions and mechanisms of formation of phenotypic differences between samples. Our network analysis results of SS and CS samples showed that greater genus community diversity and more complex interactions existed in the SS samples. The groups of phyla Cyanobacteria, Saccharibacteria and Planctomycetes were not found in the interaction network of the CS sample, and several lonely interaction units were formed in CS network (Fig. 6). Thus, the nodes in the SS network analysis were connected with more interactions than in the CS network, forming a stable network. In particular, the species of Mycobacterium, Cyanobacteria and Rhodobiaceae exhibited extensive interactions to other genera, which should be the key components that sustain the stable network, and Cyanobacteria has been confirmed to show extensive interactions with soil microbiota and play key roles in shaping the course of evolution and ecological change [26].

It is worth noting that among the main genera groups of SS and CS, there were 10 and 9 genera in the phylum Actinobacteria in SS and CS, respectively. Obviously, the phylum of Actinobacteria with important niches in SS and CS samples. Strains of Actinobacteria are effective biocontrol microorganisms against many plant pathogens, including $R$. solanacearum $[27,28]$; however, once these strains colonize on the plant surface, which can also inhibit other beneficial microbes for their broadspectrum antimicrobial compounds [29]. Thus, they can also negatively impact the bacterial community. By comparing the network analysis between SS and CS, we found that several genera are negatively correlated with the groups of Actinobacteria in SS network, such as the genera from Chloroflexi, Cyanobacteria, Planctomycetes, and Acidobacteria, as well as some genera of Proteobacteria (Bradyrhizobium, Rhodobiaceae). They can balance or limit the antagonistic effects of Actinobacteria to other microorganisms, and subsequently help construct a more stable bacterial community with greater diversity. Previous results have shown that the soil with greater bacterial community diversity facilitates microorganism nutrient cycling, promotes plant growth, adapts to environmental changes and suppresses plant pathogens [30, 31]. However, in the CS network, a significant positive correlation existed between Actinobacteria and other genera; thus, it is unfavorable to sustain the bacterial community diversity, especially once the plant-beneficial groups were inhibited, which may lead to CS fail to prevent the infection of RSSC. Thus, the main reasons for outbreak of bacterial wilt include a decline in the number of plant-beneficial groups, decreasing bacterial diversity and the accumulation of plant pathogens. Conversely, a stable and complex network existed in SS, helping to prevent RSSC infection and sustain the tomato plant health.

It has been demonstrated that $\mathrm{pH}$ has a significant impact on bacterial abundance [32]. Some related reports predicted that soil acidification could negatively affect the bacterial community stability, leading to bacterial wilt [33]. However, we found that the $\mathrm{pH}$ was lower in SS samples than in CS; therefore, other soil chemical properties may contribute to the stability of the soil bacterial community or the susceptibility to RSSC. Interestingly, we found that RAP played a vital role in the difference in the bacterial community distribution between SS and CS. Additionally, a negative correlation with the other four chemical factors was found. Thus, the RAP may function differently from other chemical factors (Fig. 5). 


\section{Conclusions}

The results of this study show that the microbial diversities were quite different between $R$. solanacearum resistant and $R$. solanacearum susceptible soils. Moreover, RAP played a key role in the difference in bacterial community distribution and was negatively correlated with $\mathrm{pH}, \mathrm{OM}$ content, $\mathrm{AHN}$, and RAK. Interaction network analysis further demonstrated that greater microbial diversity led to more extensive interactions in SS and, subsequently, a stable network. Importantly, we isolated and identified 55 bacteria strains with excellent antagonistic ability to $R$. solanacearum from the rhizosphere soil of healthy tomato plants collected from CS. This study provides a good foundation for future biological control of bacterial wilt.

\section{Methods}

\section{Collection and DNA extraction of soil samples}

Soil samples were collected from Benhao town, Lingshui country, Hainan province, China, and the collection of all of the soil samples was permissible by Lingshui country government. The SS samples were located at $\mathrm{N}$ : $18^{\circ} 29^{\prime} 51^{\prime \prime}$, E: $109^{\circ} 56^{\prime} 54^{\prime \prime}$. The CS samples were located at N: $18^{\circ} 32^{\prime} 47^{\prime \prime}, \mathrm{E}: 110^{\circ} 3^{\prime} 1^{\prime \prime}$ (Table 1). At these particular sites, cherry tomato has been continuously planted more than 5 years. First, grass at the surface was cleared in a $1 \mathrm{~m} \times 1 \mathrm{~m}$ square. The soils from $10 \mathrm{~cm}$ depth of three different locations were combined as one soil sample. Five replicate mixed soil samples were collected from healthy and diseased fields, respectively. All of the samples were stored in sterile plastic bags and transported to the laboratory in an icebox immediately. The samples were stored at $-20^{\circ} \mathrm{C}$ until $16 S \mathrm{rDNA}$ sequencing and analysis.

Aliquots $(0.25 \mathrm{~g})$ of the soil samples were processed using a MOBIO PowerSoil ${ }^{\odot}$ kit. The extracted DNA samples were analyzed using a NanoDrop 2000 UV-Vis spectrophotometer (Thermo Scientific, Wilmington, DE, USA). The DNA quality was confirmed by $1 \%$ agarose gel electrophoresis. The extracted DNA samples were selected and used to conduct microbial community analysis by PCR using the following $16 S \mathrm{rDNA}$ primers: forward (5'-GTGCCAGCMGCCGCGG-3') and reverse (5'-CCGTCAATTCMTTTRAGTTT-3') [34]. The PCR reactions were conducted as follows: $95^{\circ} \mathrm{C}$ for $3 \mathrm{~min}$; followed by 27 cycles of $30 \mathrm{~s}$ at $95^{\circ} \mathrm{C} ; 30 \mathrm{~s}$ at $55^{\circ} \mathrm{C} ; 72^{\circ} \mathrm{C}$ for $45 \mathrm{~s}$; and a final extension at $72{ }^{\circ} \mathrm{C}$ for $10 \mathrm{~min}$. The PCR reactions were performed in triplicate, using $20 \mu \mathrm{L}$ mixtures containing $4 \mu \mathrm{L} 5 \times$ FastPfu buffer, $2 \mu \mathrm{L} 2.5 \mathrm{mM}$ dNTPs, $1 \mu \mathrm{L}$ primer mix $(5 \mu \mathrm{L}), 0.4 \mu \mathrm{L}$ FastPfu polymerase, and $5 \mathrm{ng}$ extracted DNA as the template. The PCR products were extracted from a $2 \%$ agarose gel and further purified using the AxyPrep DNA Gel Extraction Kit (Axygen Biosciences, Union City, CA, USA). The products were quantified using QuantiFluor-ST (Promega, Madison, USA). Purified amplicons were then pooled in equimolar concentrations and paired-end sequenced $(2 \times 300)$ using the Illumina MiSeq platform (Illumina, San Diego, CA, USA) according to the standard protocols of Shanghai Majorbio Bio-pharm Technology Co., Ltd. Raw sequences were filtrated using FASTX Toolkit 0.0.12 software to remove low quality reads with $\mathrm{Q}$ value $<20$ and less than $35 \mathrm{bp}$ [33].

\section{Diversity analysis of microbial communities}

$16 S$ rDNA data were analyzed using the Majorbio ISanger cloud platform (http://www.i-sanger.com). The similarity and differences between samples were compared using the shared and unique OTU of a Venn diagram, and Student's t-test was used to assess the level of significant difference. The bar and pie analyses were conducted at the genus level. The PCoA of $\beta$-diversity was calculated based on the Bray-Curtis algorithm. To compare significance testing of microbial community variance of SS and CS samples at the genus level, Welch's t-test (two-tailed test) and false discovery rate were used with a Scheffe cutoff value of 0.95 . The Welch's inverted confidence interval method was used to calculate the CI value. Network analysis was conducted at the genus level to assess the correlation characterization of the SS and CS samples, and the 30 most abundant OTUs were selected. For these analyses, the Spearman correlation coefficient model was used with a cutoff of 0.5 . To conduct the $16 \mathrm{~S}$ rDNA function prediction, the richness of OTU was standardized by PICRUSt, and, subsequently, the COG family information corresponding to OTU and COG richness was obtained. The COGs with significant differences were analyzed by Stamp software (the statistical test model was an ANOVA and post hoc test model was a TukeyKramer with a cutoff 0.95 ).

\section{Correlation between soil chemical characteristics and bacterial diversity}

Soil pH, OM content, AHN, RAP, and RAK were determined as previously reported [33]. RDA was conducted to calculate the bacterial diversity distribution correlation with the above soil chemical properties at the genus level.

\section{Isolation and identification of antagonistic bacteria}

Rhizosphere soils from healthy tomato plant roots planted in CS were collected. The root tissues were shredded and ground fully with the collected rhizosphere soils. Fifty milliliters of sterile water were added to the above collecting pipe. After a series of gradient dilutions, the suspensions were spread on $\mathrm{CN}$ agar medium $(0.1 \%$ casamino acid, $0.1 \%$ nutrient broth, $1 \%$ 
agar). The dilution that resulted in 40-60 colonies per plate was selected. The colonies with different phenotypes were separated and purified. The inhibition zone method was used to assess the inhibition ability of each strain. The method is described briefly as follows: each isolated strain was cultured in the $\mathrm{CN}$ liquid medium (about $72 \mathrm{~h}, 28^{\circ} \mathrm{C}, 200 \mathrm{rpm}$ ). The $R$. solanacearum strain EP1 [35] was selected as an indicator strain. It was cultured in CPG medium (casamino acid 1\%o, peptone $1 \%$, glucose $1 \%$ ) until the $\mathrm{OD}_{600}$ was 1.0. One milliliter of EP1 suspension was added to $100 \mathrm{~mL}$ CPG agar medium (melting but not burning) and mixed well. Four microliters of the suspension of isolated rhizosphere strain were dispensed on the CPG plate with added EP1 suspension. The cells were cultured in an incubator at $28^{\circ} \mathrm{C}$. The diameters of the inhibition zone were recorded and analyzed after 3 days. All of the strains with inhibition ability were identified with $16 S$ rDNA sequencing (27F/ $1492 \mathrm{R})$, and the corresponding genus was determined based on the BLAST results of $16 S$ rRNA sequence database (Bacteria and Archaea).

\section{Assessment of microbial function of soil samples}

The SS and CS were collected and used to assess microbial function. In this study, the CS soil underwent heat treatment (autoclaving, $121^{\circ} \mathrm{C}$ for $1 \mathrm{~h}$, followed by dry heat sterilization, $180^{\circ} \mathrm{C}$ for $4 \mathrm{~h}$ ) as the control. In addition, sterile nutriment soil was inoculated with the $R$. solanacearum suspension. Five milliliters of $R$. solanacearum strain EP1 suspension $\left(\mathrm{OD}_{600} \approx 1.0\right)$ and $100 \mathrm{~mL}$ sterile water were applied to the root soil. All of the plants were placed into a climate-controlled room with a $14 \mathrm{~h} / 10 \mathrm{~h}$ light/dark cycle at $28^{\circ} \mathrm{C}$. Plants were monitored for disease progression over time after inoculation, and bacterial wilt rates were recorded. The inoculation experiments were repeated three times. Tomato plants (cultivar: Qianxi cherry tomato) were used in the above treatments.

\section{Supplementary information}

Supplementary information accompanies this paper at https://doi.org/10. 1186/s12866-020-01774-y.

Additional file $\mathbf{1} \mathbf{S 1}$. Disease incidence of tomato plants cultivated with suppressive soil (A), conducive soil with heat treatment (B), conducive soil (C), and sterile nutrition soil inoculated with $R$. solanacearum suspension (D).

\footnotetext{
Abbreviations

AHN: Alkali-hydrolyzable nitrogen; BLAST: Basic local alignment search tool: Cl: Confidence interval; CS: Conducive soil; CN: Casamino acid-nutrient broth agar; COGs: Clusters of orthologous groups; CPG: Casamino acid - peptone glucose; OM: Organic matter; OTUs: Operational taxonomic units; RAK: Rapid available potassium; RAP: Rapidly available phosphate; RDA: Redundancy analysis; RSSC: Ralstonia solanacearum species complex; SS: Suppressive soil
}

\section{Acknowledgements}

The authors thank the Mingde Lin (Benhao town, Lingshui country, Hainan Province) for his assistance of SS and CS investigation and soil collection.

\section{Consent to publication}

Not applicable.

\section{Authors' contributions}

PL, WZ collected the soil, YZ, AH contributed to isolate and identify the antagonistic strains, PL designed the experiment and wrote the paper, WZ and JZ revised the manuscript. All authors have read and approved the manuscript.

\section{Funding}

This work financially supported by the Hainan Provincial Natural Science Foundation (319QN210), National Natural Science Foundation of China (31901846), and Guangdong Province Key Laboratory of Microbial Signals and Disease Control in South China Agriculture University (MSDC2017-09). The funding bodies had no role in designing the study, sample collection, analysis, and interpretation of data or writing the manuscript

\section{Availability of data and materials}

The raw reads of 165 MiSeq data were deposited into the NCBI Sequence Read Archive database (accession No.: PRJNA564488). All the 16S rDNA sequences of 55 antagonistic strains have been upload to NCBI database (GenBank accession no. MN410647 - MN410701).

\section{Ethics approval and consent to participate}

All experiments were performed according to the experiment security regulations of Hainan Normal University, and approved by the biosafety committee in Hainan Normal University.

\section{Competing interests}

The authors declare that they have no competing interests.

Received: 31 December 2019 Accepted: 29 March 2020

Published online: 14 April 2020

\section{References}

1. Prior P, Ailloud F, Dalsing BL, Remenant B, Sanchez B, Allen C. Genomic and proteomic evidence supporting the division of the plant pathogen Ralstonia solanacearum into three species. BMC Genomics. 2016;17:90.

2. Denny TP. Plant pathogenic Ralstonia species. In plant associated Bacteria, ed. SS Gnanamanickam, pp. 573-644. Dordrecht, The Netherlands: Springer. 2006

3. Hayward AC. Biology and epidemiology of bacterial wilt caused by Pseudomonas solanacearum. Annu Rev Phytopathol. 1991;29:65-87.

4. Elphinstone JG. The current bacterial wilt situation: a global overview. In: C. Allen, P. Prior and A. C. Hayward (ed) Bacterial wilt disease and the Ralstonia solanacearum species complex. American Phytopathological Society Press, St. Paul, MN, pp 9-28; 2005.

5. Haas D, Defago G. Biological control of soil-borne pathogens by fluorescent pseudomonads. Nat Rev Microbiol. 2005;3:307-19.

6. Weller DM, Raaijmakers JM, Gardener BM, Thomashow LS. Microbial populations responsible for specific soil suppressiveness to plant pathogens. Annu Rev Phytopathol. 2002;40:309-48.

7. Li XG, Zhang YN, Ding CF, Jia ZJ, He ZL, Zhang TL, Wang XX. Declined soil suppressiveness to Fusarium oxysporum by rhizosphere microflora of cotton in soil sickness. Biol Fertil Soils. 2015;51:935-46.

8. Rosenzweig N, Tiedje JM, Quensen JF 3rd, Meng Q, Hao JJ. Microbial communities associated with potato common scab-suppressive soil determined by pyrosequencing analyses. Plant Dis. 2012;96:718-25.

9. Hunter PJ, Petch GM, Calvo-Bado LA, Pettitt TR, Parsons NR, Morgan JA, Whipps JM. Differences in microbial activity and microbial populations of peat associated with suppression of damping-off disease caused by Pythium sylvaticum. Appl Environ Microbiol. 2006;72:6452-60.

10. Millennium Ecosystem Assessment Program. Ecosystems and human wellbeing:wetlands and water synthesis: a report of the millennium ecosystem assessment [M]: Island Press; 2005.

11. Yoshitaka S, Masaya N, Tomoko O, Takuya M. Comparison of bacterial community structures in the rhizoplane of tomato plants grown in soils 
suppressive and conducive towards bacterial wilt. Appl Environ Microbiol. 1999:65:3996-4001.

12. Kwak MJ, Kong HG, Choi K, Kwon SK, Song JY, Lee J, Lee PA, Choi SY, Seo $\mathrm{M}$, Lee $\mathrm{HJ}$, et al. Rhizosphere microbiome structure alters to enable wilt resistance in tomato. Nat Biotechnol. $2018 .$.

13. van Elsas JD, Chiurazzi M, Mallon CA, Elhottova D, Kristufek V, Salles JF. Microbial diversity determines the invasion of soil by a bacterial pathogen. Proc Natl Acad Sci U S A. 2012;109:1159-64.

14. Tian T, Wu XG, Duan HM, Zhang LQ. The resistance-nodulation-division efflux pump EmhABC influences the production of 2,4diacetylphloroglucinol in Pseudomonas fluorescens 2P24. Microbiology. 2010; 156:39-48.

15. Hu J, Wei Z, Friman VP, Gu SH, Wang XF, Eisenhauer N, Yang TJ, Ma J, Shen $\mathrm{QR}, \mathrm{Xu}$ YC, et al. Probiotic diversity enhances rhizosphere microbiome function and plant disease suppression. mBio. 2016;7:1-8.

16. Wang R, Zhang H, Sun L, Qi G, Chen S, Zhao X. Microbial community composition is related to soil biological and chemical properties and bacterial wilt outbreak. Sci Rep. 2017;7:343.

17. Zheng X, Liu B, Zhu Y, Wang J, Zhang H, Wang Z. Bacterial community diversity associated with the severity of bacterial wilt disease in tomato fields in south-East China. Can J Microbiol. 2019;65:1-12.

18. Shen G, Zhang S, Liu X, Jiang Q, Ding W. Soil acidification amendments change the rhizosphere bacterial community of tobacco in a bacterial wilt affected field. Appll Microbiol Biotechnol. 2018;102:9781-91.

19. Ongena M, Jacques P. Bacillus lipopeptides: versatile weapons for plant disease biocontrol. Trends Microbiol. 2008;16:115-25.

20. Tahir HA, Gu Q, Wu H, Niu Y, Huo R, Gao X. Bacillus volatiles adversely affect the physiology and ultra-structure of Ralstonia solanacearum and induce systemic resistance in tobacco against bacterial wilt. Sci Rep. 2017;7:40481.

21. Asaka O, Shoda M. Biocontrol of Rhizoctonia solani damping-off of tomato with Bacillus subtilis RB14. Appl Environ Microbiol. 1996;62:4081-5.

22. Leclere V, Bechet M, Adam A, Guez JS, Wathelet B, Ongena M, Thonart P, Gancel F, Chollet-Imbert M, Jacques P. Mycosubtilin overproduction by Bacillus subtilis BBG100 enhances the organism's antagonistic and biocontrol activities. Appl Environ Microbiol. 2005;71:4577-84.

23. Romero D, de Vicente A, Rakotoaly RH, Dufour SE, Veening J-W, Arrebola $\mathrm{E}_{t}$ Cazorla FM, Kuipers OP, Paquot M, Pérez-García A. The iturin and fengycin families of lipopeptides are key factors in antagonism of Bacillus subtilis toward Podosphaera fusca. Mol Plant-Microbe Interact. 2007;20:430-40.

24. Philippot L, Raaijmakers JM, Lemanceau P, van der Putten WH. Going back to the roots: the microbial ecology of the rhizosphere. Nat Rev Microbiol. 2013;11:789-99.

25. Berendsen RL, Vismans G, Yu K, Song Y, de Jonge R, Burgman WP, Burmolle M, Herschend J, Bakker P, Pieterse CMJ. Disease-induced assemblage of a plant-beneficial bacterial consortium. ISME J. 2018;12:1496-507.

26. Chaffron S, Rehrauer H, Pernthaler J, von Mering C. A global network of coexisting microbes from environmental and whole-genome sequence data. Genome Res. 2010;20:947-59.

27. Tan HM, Zhou SN, Deng ZJ, He M, Cao LX. Ribosomal-sequence-directed selection for endophytic streptomycete strains antagonistic to Ralstonia solanacearum to control tomato bacterial wilt. Biol Control. 2011:59:245-54.

28. Barka EA, Vatsa P, Sanchez L, Gaveau-Vaillant N, Jacquard C, Meier-Kolthoff JP, Klenk HP, Clement C, Ouhdouch Y, van Wezel GP. Taxonomy, physiology, and natural products of Actinobacteria. Microbiol Mol Biol Rev. 2016;80:1-43.

29. Elbendary AA, Hessain AM, El-Hariri MD, Seida AA, Moussa IM, Mubarak AS, Kabli SA, Hemeg HA, El Jakee JK. Isolation of antimicrobial producing Actinobacteria from soil samples. Saudi J Biol Sci. 2018;25:44-6.

30. Samac DA, Willert AM, McBride MJ, Kinkel LL. Effects of antibiotic-producing Streptomyces on nodulation and leaf spot in alfalfa. Appl Soil Ecol. 2003;22: 55-66.

31. de Ruiter PC, Neutel A-M, Moore JC. Energetics, patterns of interaction strengths, and stability in real ecosystems. Science. 1995;269:1257-60.

32. Bartram AK, Jiang XP, Lynch MDJ, Masella AP, Nicol GW, Dushoff J, Neufeld JD. Exploring links between $\mathrm{pH}$ and bacterial community composition in soils from the Craibstone experimental farm. FEMS Microbiol Ecol. 2014;87:403-15.

33. Qi G, Ma G, Chen S, Lian C, Xiuyun Z. Microbial network and soil properties are changed in bacterial wilt susceptible soil. Appl Environ Microbiol 2019: DOI: 10.1128/AEM.00162-00119.

34. Lane DJ. 16S/23S rRNA sequencing, p. 115-147. In E. Stackebrandt and M. Goodfellow (ed.), Nucleic acid techniques in bacterial systematics. Wiley, Chichester, United Kingdom; 1990.
35. Li P, Wang DC, Yan JL, Zhou JN, Yue DY, Jiang ZD, Cao BH, He ZF, Zhang L$\mathrm{H}$. Genomic analysis of phylotype I strain EP1 reveals substantial divergence from other strains in the Ralstonia solanacearum species complex. Front Microbiol. 2016;7:01719.

\section{Publisher's Note}

Springer Nature remains neutral with regard to jurisdictional claims in published maps and institutional affiliations.
Ready to submit your research? Choose BMC and benefit from:

- fast, convenient online submission

- thorough peer review by experienced researchers in your field

- rapid publication on acceptance

- support for research data, including large and complex data types

- gold Open Access which fosters wider collaboration and increased citations

- maximum visibility for your research: over $100 \mathrm{M}$ website views per year

At BMC, research is always in progress.

Learn more biomedcentral.com/submissions 